http://dx.doi.org/10.18675/1981-8106.vol26.n51.p19-35

\title{
Educação Física Escolar e Gênero: Influências de fora da escola na participação em aulas.
}

\author{
School Physical Education and Gender: Influences from outside the school at \\ participation in classes.
}

Educación Física Escolar y Género: Influencias de fuera de la escuela en la participación en las clases.

\author{
Juliana Fagundes Jaco ' \\ Helena Altmann " \\ ' Universidade Estadual de Campinas (UNICAMP), São Paulo - Brasil. E-mail: julianafef@gmail.com \\ "Universidade Estadual de Campinas (UNICAMP) São Paulo - Brasil. E-mail: \\ altmann@fef.unicamp.br
}

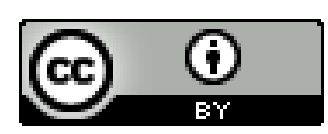

Educação: teoria e prática, Rio Claro, SP, Brasil - eISSN: 1981-8106

Está licenciada sob Licença Creative Common

\section{Resumo}

A participação em aulas de educação física é assunto complexo, pois inúmeros fatores levam alunos/as a participarem das atividades de aula de diferentes maneiras. Esta pesquisa analisa como que a maneira de participar da aula é influenciada por experiências advindas fora da escola. Neste caminho, busca analisar as seguintes questões: como que as ações e discursos familiares influenciam nas diferentes participações de meninas e meninos, como que as participações em atividades corporais fora da escola, em instituições formais de ensino, influenciam nas participações, e, ainda, como que expectativas e entendimentos sobre práticas corporais para cada gênero influência participações distintas quando comparamos meninos e meninas. Para isso, foram realizadas entrevistas semiestruturadas e observações de aulas em quatro turmas de $8^{\circ}$ ano de duas escolas públicas do município de Campinas-SP. Os apontamentos desta pesquisa indicaram que as experiências e conhecimentos sobre o corpo e 
o movimento trazidas de fora da escola exercem grande influência sobre qual lugar alunos/as ocupavam nas aulas. O meio cultural no qual estavam inseridos/as possibilitou experiências e entendimentos distinto para cada um/a sobre os saberes que circulam nas aulas de educação física, sobre corpo e gênero e que contribuíram nas diferentes maneiras de participar das aulas.

Palavras chave: Educação Física, Gênero, Participação

\begin{abstract}
Participation in physical education classes is a complex issue; many factors lead students to participate in classroom activities in different ways. This research examines how the way to take part in the class is influenced by experiences outside of school. In this way, seeks to analyze how the actions and family discourses influence the different interests of girls and boys, such as the participation in physical activities outside of school. Also, examines the influence of the participating inside of the school, and how expectations and understandings of bodily practices for boys and girls influence different ways to participate in classes when comparing the male and female gender. For this, held semi-structured interviews and classroom observations into four groups of the eighth year of two public schools in the city of Campinas-SP. The notes of this research indicated that the experience and knowledge of the body and body practice outside of school have the big influence on the ways of participating in classes. The cultural environment of the students gave different experiences and understandings for boys and girls in the knowledge that circulate in physical education classes and contributed in different ways to participate in class.
\end{abstract}

Keywords: Physical Education, Gender, Participation

\title{
Resumen
}

La participación en las clases de educación física es un asunto complejo, pues innúmeros factores llevan a alumnos/as a participar de las actividades de la clase de diferentes maneras. Esta investigación analiza cómo la manera de participar de la clase es influenciada por las experiencias de fuera de la escuela. En este camino, se busca analizar las siguientes cuestiones: cómo las acciones y discursos familiares influencian en las diferentes participaciones de niñas y niños, cómo las participaciones en actividades corporales fuera de la escuela en instituciones formales de enseñanza influencian en las participaciones, e, incluso, cómo las expectativas y entendimientos sobre prácticas corporales para cada género influencian participaciones distintas cuando comparamos niños y niñas. Para esto, se realizaron entrevistas semiestructuradas y observaciones de clases en 
cuatro grupos de $8^{o}$ año de dos escuelas públicas del municipio de Campinas-SP. Las anotaciones de esta investigación indicaron que las experiencias y conocimientos sobre el cuerpo y el movimiento traídos de fuera de la escuela ejercen una gran influencia sobre qué lugar los alumnos/as ocupaban en las clases. El medio cultural en el que estaban inseridos/as posibilitó experiencias y entendimientos distintos para cada uno/a sobre los saberes que circulan en las clases de educación física, sobre cuerpo y género, y que contribuyeron en las diferentes maneras de participar de las clases.

Palabras clave: Educación Física, Género, Participación

\section{Introdução:}

Para o aprendizado dos conteúdos da educação física escolar é necessário, entre outras coisas, criar situações nas quais o corpo e o movimento estejam envolvidos de maneira significativa. Isso porque a especificidade dessa área de conhecimento está justamente no corpo e no movimento. Sobre isso, Bracht (1999) diz que a educação física busca ser um saber fazer, um realizar corporal e, ao mesmo tempo, busca ser um saber sobre este realizar corporal. A Educação Física tem ainda como função possibilitar o acesso aos saberes relativos à Ginástica, Jogos, Esportes, Dança, Lutas, Capoeira, e esse acesso deve ser feito considerando as diferentes dimensões que o envolvem esses saberes: histórica, social, técnica (o saber fazer) e, também, a dimensão lúdica (SOARES, 1996). Portanto, participar da aula de educação física e das atividades propostas em aula de maneira que o corpo esteja em movimento é entendido como um dos elementos fundamentais, mas não exclusivos, para o aprendizado de seus conteúdos.

Portanto, a não participação nas aulas é um problema que inquieta muitos/as professores/as e é objeto central das reflexões desse artigo, que reflete sobre questões que podem influenciar na maneira como alunos/as participam das aulas de educação física. A partir de tais reflexões, busca auxiliar na compreensão sobre as diferentes formas de participação de alunos/as nas aulas de educação física, apresentando especificamente um recorte que mostra como que questões de fora da escola influenciam na maneira como que alunos e alunas participam da aula e como tais questões perpassam pelo Gênero.

No entanto, para pensar sobre participações em aulas deve-se ir além do olhar baseado na lógica binária: Participar x Não participar. Isso porque tal lógica é pautada na referência sobre se o/a aluno/a está dentro ou fora da atividade, referência que é falha, pois considera a não participação nas aulas somente como a exclusão física da atividade sem atentar-se para diversas outras maneiras de estar a margem do processo de ensino aprendizado. Além disso, essa lógica é reducionista, pois como problematiza Oliveira (2010), bastaria a simples solução de integrar quem está fora da atividade ao restante da turma para se 
resolver a situação. Sendo assim, apesar da exclusão física da atividade ser uma forma de não participar das aulas, existem outras estratégias e formas de não participar das aulas que colocam alunos/as às margens do ensino-aprendizado.

Quando se pensa em participações nas aulas de educação física, outro ponto que também deve ser considerado nas reflexões é que inúmeras pesquisas apontam que o desinteresse e a menor participação são mais comuns entre meninas (ANDRADE e DEVIDE, 2006; DELGADO e PARANHOS, 2009; JACÓ, 2008; PEREIRA e MOREIRA, 2005). Como foi o caso constatado na pesquisa sobre a não participação em aulas de educação física realizada com alunos e alunas de oitavos e nonos anos de quatro escolas publicas de Campinas-SP. Nesta pesquisa viu-se que de 82 pessoas entrevistadas por não estarem participando das aulas de educação física 67 eram meninas. (JACO, 2008)

Portanto, para pensar sobre as relações que se estabelecem nas aulas de educação física, é importante que também se olhe para o que alunos e alunas trazem de fora, a partir de outras experiências, vivências, realidades e que contribuem e interferem nas suas ações e relações com a aula de educação física. Sendo assim, esse artigo apresenta algumas reflexões sobre como que vivências que ocorrem fora da escola influenciam nas maneiras de alunos/as participarem das aulas. Isso porque as relações que se estabelecem na escola e nas aulas de educação física têm grande influência na vida de alunos e alunas, mas não são a única fonte de formação dos sujeitos no que se refere às práticas corporais.

Sendo assim, é necessário o entendimento de que alunos/as são seres culturais, ou seja, conforme apresenta Geertz (1989), é necessário que se entenda que todo ser humano é amarrado em teias de significados e a cultura seria essas teias e suas significações. Os alunos e alunas que estão na escola atribuem significado às diferentes práticas corporais, não somente pelas informações que a escola e, mais especificamente, a educação física fornecem. Mas também pelos sentidos, vivências, valores, normas, que a cultura na qual estão inseridos/as entende tais práticas corporais, ou seja, por uma rede de representações que vai moldando cada aspecto da vida social, inclusive sobre os saberes que circulam nas aulas de educação física, pois sabe-se "que toda prática social tem uma dimensão cultural" (HALL, 1997, p.33).

Assim, não são somente as informações que adquirem nas aulas de educação física que compõem os sentidos atribuídos por alunos/as às práticas corporais e à própria aula. Antes mesmo de entrar na escola, alunas e alunos já vivenciam seus corpos de diversas maneiras e intensidades distintas.

Convivemos diariamente com os diversos grupos sociais e culturais, ou seja, nossos pais, amigos, com o grupo escolar etc. Sendo assim, todas as nossas representações de corpo são construídas social $e$ culturalmente, expondo, em certa medida, a questão da diversidade 
corporal existente na sociedade e consequentemente na escola. (RIGONI, 2010, p.137)

A autora mostra ainda como as relações que alunas e alunos têm com seus corpos são influenciadas por vivências culturais de outros contextos sociais, tendo impacto na escola. Até mesmo o entendimento que alunas e alunos têm sobre as práticas corporais e as aulas de educação física são formadas por diferentes fontes de informação, sejam elas as mídias, a própria escola, o/a professor/a de educação física e suas aulas, as relações sociais e a família e suas experiências pessoais com o corpo e o movimento. Essa visão sobre as aulas de educação física e as práticas corporais pode influenciar também nas maneiras como os sujeitos vivenciam seus corpos na escola e nas aulas.

Por meio de entrevistas e observações de aulas essa pesquisa buscou identificar como que as ações e discursos familiares influenciam nas participações e entendimentos de meninas e meninos nas maneiras de ser e estar no tempo e espaço das aulas de educação física. Buscou-se identificar também como que as participações em atividades corporais fora da escola em instituições formais de ensino influenciam nas participações nas aulas. E, ainda, como que expectativas e entendimentos sobre práticas corporais para cada gênero influenciam participações distintas quando comparamos meninos e meninas.

Gênero compreendido como "Um elemento constitutivo das relações sociais fundadas sobre as diferenças percebidas entre os sexos, que fornecem um meio de decodificar o significado e compreender as complexas formas de interação humana" (SCOTT, 1995, p.89). Sendo assim, gênero pode ser entendido como construções culturais das diferenças tendo como ponto de partida as diferenças percebidas entre os sexos pensados em uma lógica binária: masculino e feminino.

Butler (2003), no entanto, nos faz pensar o quanto essa lógica binária é falha, pois existem inúmeras pessoas que "escapam” a ela. A lógica binária das identidades de gênero é construída a partir do referencial biológico e médico que constrói verdades, mas para Butler as identidades de gênero não são espaços fixos, e sim de constantes diálogos, de tensões e negociações, que extrapolam essa lógica binária e que há sempre aqueles que rompem com essas barreiras do que se entende por feminino e masculino.

\section{A pesquisa}


Essa pesquisa ocorreu com aprovação do Comitê de Ética em Pesquisa da universidade que está vinculada e obteve o parecer de aprovação registrado em 146/2010. Foram entregues Termos de Consentimento Livre e Esclarecido (TCLE) para a Direção das escolas, para professores/as e para alunos/as que levaram para que seus responsáveis legais assinassem. Todos os nomes utilizados na pesquisa são fictícios para preservar a identidade dos envolvidos, inclusive os nomes das escolas foram trocados.

As informações e análises apresentadas aqui surgiram após a realização de entrevistas e observações realizadas com alunas, alunos e professores/as de duas escolas públicas estaduais localizadas no município de Campinas-SP. Em cada escola, a pesquisa ocorreu em duas turmas de oitavo ano.

As entrevistas tiveram como foco ouvir os sujeitos em seus contextos e conhecer como tais sujeitos compreendem as relações que lá se estabelecem e ouvir as opiniões, compreensões e histórias de vida. As entrevistas foram do tipo Semiestruturadas, na qual se seguiu um roteiro de perguntas que, no entanto, permitiu certa liberdade para conduzir a entrevista de acordo com as situações. As entrevistas ocorreram durante o horário da aula, no mesmo local e foram gravadas por um gravador de voz.

A permanência em cada escola foi de 2 meses, divididos em observações e entrevistas. As observações das aulas tiveram o objetivo de ser uma ferramenta para auxiliar na organização e realização das entrevistas e na elaboração das análises. Durante as observações, conheceram-se a dinâmica, organização e estrutura das aulas, as turmas e seus perfis. Foi durante as observações que identificou-se como se davam as participações e não participações, ou seja, quem participava, como participava e o oposto também. A partir dessas observações na maneira como participavam da aula, a pesquisadora organizou os alunos/as por grupos, de acordo com as formas de participação e identificou-se nesses grupos quem havia autorização para participar das entrevistas. As entrevistas com alunos/as foram realizadas em duplas, para que eles/as se sentissem mais à vontade e menos intimidados pela formalidade do processo. Essas duplas foram formadas pela pesquisadora de acordo com o agrupamento realizado pela semelhança na maneira de participar das aulas.

Os grupos identificados por formas de participação naquelas aulas foram chamados de: Protagonistas, Figurantes, Flutuantes e Excluídos/as. O grupo de Protagonistas foi composto por quem participava ativamente de todas as aulas. As pessoas desse grupo corriam atrás da bola, realizavam passes, negociavam as regras com a/o professor/a, executavam com ânimo e dedicação as propostas. Nunca estavam na periferia da quadra e em nenhuma aula se colocaram fisicamente fora da atividade de aula.

O grupo de Excluídos/as foi composto por alunos/as que se colocavam fisicamente fora da atividade de aula, grupo que se colocava nos degraus da arquibancada, ouvia música, conversava, não interagia com a atividade de aula. 
O grupo de Figurantes foi um grupo também às margens do processo de ensino aprendizado, porém esse grupo foi composto por alunos/as que não se colocavam fisicamente fora da atividade de aula, mas que ocupavam a periferia da aula e/ou da atividade, pois não se posicionavam de forma ativa durante o jogo, fazendo até mesmo, outras coisas em quadra, como conversar com o colega, arrumar o cabelo, evitavam pegar a bola nos jogos observados. Em atividades de circuito, posicionavam-se na fila, mas com a proximidade da sua vez, iam deixando outra pessoa passar na frente, permanecendo na fila sem realizar o proposto.

Também havia outro grupo que estava na periferia dessas aulas: grupo aqui nomeado como Flutuante. Ele era formado por quem, em algumas aulas ficava como Figurante nas atividades, em outros momentos participava ativamente, ou ainda excluía-se do proposto, ou seja, quem não se colocava fixamente em nenhum grupo, mas flutuava, passeava, entre os outros grupos que configuravam aquele espaço de aula.

Com base na observação dessas diferentes maneiras de participar das aulas, as entrevistas foram realizadas e aqui serão apresentados dados e análises para compreensão de como que influências de fora da escola colaboram para que alunos/as tenham diferentes maneiras de participar das aulas de educação física.

\section{Resultados e discussões:}

Os dados apresentados a seguir estão em três eixos de análise de assuntos que se sobressaíram nas entrevistas como questões de fora da escola que interferem na maneira como alunos/as participam das aulas. São elas: 1) O Apoio Social da família. 2) Práticas Corporais vivenciadas fora da escola. 3)Entendimentos sobre as práticas corporais para meninos e meninos.

1) O apoio social da família

Durante as entrevistas, buscou-se verificar, entre outras questões, como a família atua dando apoio social para alunas/os participarem das aulas de educação física e/ou práticas corporais fora escola, fosse em instituições formais como Academias, Clubes, e "Escolinhas"1 ou em momentos livres, como prática de lazer em ruas, parques etc. Nesta pesquisa, foi considerado como "Apoio Social" os incentivos verbais e em ações diretivas recebidos pelos/as alunos/as. Para saber sobre isso, durante as entrevistas, questionou-se ao entrevistado/a se percebia receber apoio de seus familiares, questionou-se como percebia receber esse apoio, o que seus familiares falavam e o que faziam em relação a esse assunto.

\footnotetext{
${ }^{1}$ Nesse termo estão sendo consideradas atividades regulares, formais, em instituições como clubes, academias etc, que têm o foco no ensino-aprendizagem e treinamento de modalidades esportivas, também conhecidas por "Escolas de Esporte". A opção na utilização do termo "Escolinha" foi feita por ser assim que nas escolas pesquisadas os/as alunos/as e professor/a se referiram a essa prática.
} 
Na escola Marta foram entrevistados/as 10 protagonistas (08 meninos e 02 meninas). Nessa entrevista obtivemos os seguintes dados:

\section{Quadro 1- Apoio Social da família para o grupo Protagonistas na Escola Marta}

\begin{tabular}{|c|c|c|c|c|}
\hline Entrevistado/a & $\begin{array}{c}\text { Recebe } \\
\text { apoio para } \\
\text { educação } \\
\text { física }\end{array}$ & $\begin{array}{c}\text { Recebe apoio para } \\
\text { participar de } \\
\text { atividades } \\
\text { institucionalizadas }\end{array}$ & $\begin{array}{c}\text { Recebe apoio } \\
\text { para } \\
\text { atividades } \\
\text { livres }\end{array}$ & $\begin{array}{c}\text { Não recebe } \\
\text { nenhum } \\
\text { apoio }\end{array}$ \\
\hline Artur & $\mathrm{X}$ & $\mathrm{X}$ & & \\
\hline Eliza & & $\mathrm{X}$ & & \\
\hline Guilherme & $\mathrm{X}$ & $\mathrm{X}$ & & \\
\hline João & & $\mathrm{X}$ & & \\
\hline Milena & & $\mathrm{X}$ & & \\
\hline Marcio & & & $\mathrm{X}$ & \\
\hline Luís & & $\mathrm{X}$ & $\mathrm{X}$ & \\
\hline Diego & & & & \\
\hline Fidelis & & & & \\
\hline Gustavo & & & & \\
\hline
\end{tabular}

O quadro mostra que somente duas pessoas consideram que recebem o apoio de familiares para assumirem uma postura de protagonistas nas aulas observadas na Escola Marta, sendo duas meninas. Apontando para o fato de que os incentivos da família não foram determinantes para que os alunos participem ativamente das aulas, no entanto, pareceu como algo relevante para a participação das meninas Protagonistas, pois, além delas receberem apoio para participar das aulas, recebem também apoio para realizar atividades institucionalizadas fora da escola, parecendo ser as práticas corporais algo relevante no seu contexto de vida.

O grupo de Protagonistas nas duas escolas pesquisadas, de maneira geral, recebeu mais apoio para atividades fora da escola. Isso foi encontrado em vários relatos de alunos/as como, por exemplo, o aluno Artur e Márcio. O aluno Artur, quando perguntado se recebia algum tipo de apoio de sua família para participar da aula de educação física, respondeu: Para Educação Física não, mas para escolinha de futebol. 
Situação um pouco diferente apareceu nos demais grupos. O grupo Figurante nessa escola era formado por meninas, nove no total. Desse número três dizem que não recebem nenhum tipo de apoio (nem para participar das aulas de educação física e nem mesmo para atividades fora da escola). Uma garota afirmou receber apoio para participar das aulas de educação física. Duas disseram que a família incentiva a prática de atividade institucionalizada, mas nenhuma delas de fato frequenta essas atividades.

Quadro 2. Apoio Social da família para o grupo de Figurantes na Escola Marta

\begin{tabular}{|c|c|c|c|c|}
\hline Entrevistada & $\begin{array}{l}\text { Recebe apoio } \\
\text { para educação } \\
\text { física }\end{array}$ & $\begin{array}{l}\text { Recebe apoio para } \\
\text { participar de } \\
\text { atividades } \\
\text { institucionalizadas }\end{array}$ & $\begin{array}{c}\text { Recebe apoio } \\
\text { para atividades } \\
\text { livres }\end{array}$ & $\begin{array}{c}\text { Não recebe } \\
\text { nenhum } \\
\text { apoio }\end{array}$ \\
\hline Catia & & $\mathrm{X}$ & & \\
\hline Guilhermina & $\mathrm{X}$ & & & \\
\hline Livia & & & & $\mathrm{X}$ \\
\hline Marcia & & $\mathrm{X}$ & & \\
\hline Amanda & & & & $\mathrm{X}$ \\
\hline Julia & & & $X$ & \\
\hline Branca & & & & $\mathrm{X}$ \\
\hline Aline & & & $\mathrm{X}$ & \\
\hline Sueli & & & $\mathrm{X}$ & \\
\hline
\end{tabular}

Já o grupo de Flutuantes na escola Marta, também formada exclusivamente por meninas apresenta os seguintes dados:

Quadro 3. Apoio Social da família para o grupo de Flutuantes na Escola Marta

\begin{tabular}{|c|c|c|c|c|}
\hline Entrevistada & $\begin{array}{c}\text { Recebe apoio } \\
\text { para educação } \\
\text { física }\end{array}$ & $\begin{array}{c}\text { Recebe apoio para } \\
\text { participar de } \\
\text { atividades }\end{array}$ & $\begin{array}{c}\text { Recebe apoio } \\
\text { para atividades } \\
\text { livres }\end{array}$ & $\begin{array}{c}\text { Não recebe } \\
\text { nenhum apoio }\end{array}$ \\
\hline
\end{tabular}




\begin{tabular}{|c|c|c|c|c|}
\hline & & institucionalizadas & & \\
\hline Lorena & & & $\mathrm{X}$ & \\
\hline Marta & $\mathrm{X}$ & & $\mathrm{X}$ & \\
\hline Joana & & & $\mathrm{X}$ & \\
\hline Talita & & & & $\mathrm{X}$ \\
\hline Maria & & & & $\mathrm{X}$ \\
\hline Brenda & & & & \\
\hline
\end{tabular}

Mas o que os dados desses quadros todos nos dizem? Todos esses dados vão apontando um caminho do que é valorizado pelos familiares desses alunos e alunas no que se refere às práticas corporais. Ao pensarmos no que é valorizado pelos familiares em relação às práticas corporais podemos pensar quais são os entendimentos e significados que o meio familiar atribui para as práticas corporais, qual o lugar da educação física para essas pessoas e como isso se relaciona com o gênero.

Percebe-se uma escassa quantidade de referências positivas da família no que se trata da educação física escolar. No total foram entrevistadas 15 meninas que possuem pouca participação nas aulas de educação física na Escola Marta (dado obtido somando o grupo de Flutuantes e Figurantes) somente duas meninas recebem apoio social para participar das aulas de educação física e duas para práticas formais fora da escola. Ou seja, para as meninas o apoio social da família para participar de práticas corporais na escola e em "Escolinhas de Esportes" é algo que faz diferença no cotidiano das aulas, visto que as meninas protagonistas recebem apoio social tanto para as práticas na escola como em "Escolinhas de Esportes".

Outro ponto que merece uma reflexão é que há uma diferença significativa nos direcionamentos do apoio social para as práticas corporais realizadas fora da escola. A maioria do grupo Protagonista recebe apoio para atividades em "Escolinhas" enquanto que para as Figurantes e Flutuantes a maior parte do apoio foi para práticas livres, como brincar na rua, andar de bicicleta e caminhar, por exemplo.

Essas situações não foram diferentes na escola Paula, na qual foram entrevistados/as 33 alunos/as. Nessa segunda escola foram entrevistados 11 pessoas consideradas Protagonistas, dessas pessoas, 07 eram meninos e 04 meninas. Nesse grupo, 07 pessoas recebem apoio para atividades institucionalizadas e 02 para a prática da educação física na escola. Já no grupo de Figurantes, representado por cinco meninas entrevistadas, três citaram receber algum apoio para algum tipo de prática corporal, uma não recebe nenhum apoio e outra não citou em sua fala. 
2) Práticas corporais vivenciadas fora da escola

Diante dos dados apresentados até aqui nota-se que as diferenças nas maneiras como a família direciona o apoio social e proporciona experiências de alunos e alunas com a prática corporal pode exercer influência na maneira como alunos e alunas atuam nas aulas de educação física. Percebe-se, analisando as entrevistas, que o grupo de Protagonistas recebe incentivo mais efetivo, diretivo para a prática de atividades corporais e que se materializa, inclusive, no fato de que de 10 Protagonistas da Escola Marta, sete alunos/as realizam atividades fora da escola em instituições formais (70\%). Na Escola Paula, das 12 pessoas protagonistas, sete afirmaram estar frequentando atividades formais $(58,6 \%)$. Em alguns casos, inclusive, praticam mais de uma modalidade.

Quadro 4. Quantidade de Protagonistas por Atividade.

\begin{tabular}{|c|c|c|}
\hline ATIVIDADE & MENINAS & MENINOS \\
\hline Futebol & 01 & 07 \\
\hline Vôlei & 02 & 00 \\
\hline Judô & 01 & 02 \\
\hline Tênis & 00 & 02 \\
\hline Handebol & 01 & 00 \\
\hline Ballet & 02 & 00 \\
\hline Gin. Artística & 01 & 00 \\
\hline
\end{tabular}

No geral, os/as integrantes do grupo de Protagonistas participam de atividades formais fora da escola enquanto que, nos demais grupos, esse número foi muito baixo. Além disso, os esportes são os itens mais citados pelos meninos, principalmente o Futebol. Já as meninas têm suas práticas mais diversificadas, sendo tanto atividades esportivas quanto ginástica e Ballet.

Incentivos nas formas de ações diretivas proporcionam experiências e repertórios com o corpo e o movimento que possibilitam mais sucesso nas aulas de educação física quando comparados com aqueles/as com menos experiências fora da escola. Aqueles/as que vivenciam práticas corporais fora da escola possuem mais tempo de prática, mais experiências corporais, o que possibilita uma diferenciação nas habilidades quando comparados com quem tem poucas experiências. 
Aqueles/as que possuem um tempo maior em práticas corporais, principalmente com experiências com práticas esportivas em outras instituições, possuem um maior pertencimento nas aulas de educação física, uma vez que estão estabelecidos nos conteúdos das aulas há mais tempo, ou seja, possuem mais experiências com os temas da aula e já conhecem os assuntos tratados. Essas pessoas acabam formando grupos de liderança e muitas vezes excluindo quem não sabe e que são considerados menos hábeis e "incompetentes". Valle (1992) diz que "O erro marca o aluno como 'aquele que não consegue aprender', aquele que é estigmatizado e, portanto, ganha rótulo de incompetente" (VALLE, 1992, p. 21). A autora nos diz ainda que "os que sabem são os que detêm o poder" (VALLE, 1992, p. 27). Penso que o que a autora apresenta também pode ser entendido na aula de educação física, por exemplo, na forma da participação mais ativa, no maior tempo de posse de bola, em mais iniciativa e comando de jogo da parte de alguns alunos e algumas alunas.

Observou-se nas aulas que as meninas e meninos que "não sabem", acabavam tendo poucas oportunidades de vir a saber, sendo excluídas do jogo ou se auto-excluindo, como diz uma aluna: "As vezes um saber jogar, então quando pega a bola fica só com ele, não divide com ninguém e o outro acaba desistindo" (Márcia). Em outra fala vemos o mesmo: "Tem gente que treina vôlei. E a gente não sabe jogar. E quem sabe fica fazendo cara feia, comentariozinho!"' (Aluna Talita).

3) Diferentes entendimentos sobre as práticas corporais para meninos e meninos.

Olhando para os dados dos quadros trazidos anteriormente, já foi possível visualizar que existem diferenças nos incentivos recebidos por quem ocupa o lugar de Protagonista nas aulas e por quem ocupa os lugares de Figurante, Flutuante e Excluído. O incentivo desses três últimos grupos foi direcionado para práticas em momentos livres e não institucionalizadas.

As práticas que ocorrem em momentos livres e não são institucionalizadas ocorrem sem mediação e intervenção de professores/as, além disso, ocorrem sem sistematização, organização e avaliação. São práticas voltadas para o divertimento e, em alguns casos, com preocupações estéticas e voltadas para a saúde, ou seja, sem focar e privilegiar processos de ensino e aprendizagem que outras situações, como a escola e as "escolinhas", privilegiam e que sua existência se justifica justamente atrelada ao sentido de serem instituições de ensino e aprendizado.

Tais diferenças vão oportunizando repertórios de conhecimentos sobre as práticas corporais bastante distintos entre meninos e meninas. Isso porque, apesar de durante a prática voltada para o divertimento, para a estética e/ou saúde proporcionarem também conhecimentos, são saberes diferenciados quando comparados com os saberes organizados, sistematizados, formalizados que circulam na escola e na "escolinha". Tal dado pode ser entendido analisando a seguinte ideia: ao receberem o apoio social direcionado a práticas 
livres e para saúde e/ou estética, muitas meninas vão construindo um repertório corporal diferenciado em comparação com quem participa de espaços voltados para o aprendizado de modalidades esportivas, que foram as práticas mais incentivadas para os meninos. De acordo com as entrevistas, pode-se perceber que as meninas são, sobretudo, direcionadas a promoverem um estilo de vida ativo que é parte de uma cultura fitness. Goellner (2009) situa a cultura fitness como:

um conjunto de dispositivos que opera em torno da construção de uma representação de corpo que conjuga como sinônimos "saúde" $e$ "beleza", associando-os a termos representados como plenos de positividades, entre eles, "bem-estar", "qualidade de vida" e "vida sustentável” (GOELLNER, 2009, p.283).

Podendo dizer que a cultura fitness envolve várias formas de intervenções, discursos, práticas para promoção de uma ideia, um estilo de vida, uma atitude, tanto para homens quanto mulheres. Mas é importante observar que nesses discursos as meninas são tidas como sendo as responsáveis em sempre manterem-se no padrão desejado. O fitness se concilia com a feminilidade como repositório da normatividade; quer dizer, reformulam certas ideias sobre o corpo feminino, suas formas e sua capacidade, alterando algumas fronteiras ou parâmetros (por exemplo, permitem-se uma 'força' e musculatura 'femininas'), mas sem se libertar de definições altamente normativas do masculino e do feminino e sem abrir mão de todo um sistema de autovigilância que a manutenção da feminilidade exige. (ALDEMANN, 2003, p.462)

Esse entendimento por parte da família de que as meninas devem preocupar-se com sua beleza e saúde foi visto, por exemplo, na fala de duas meninas da Escola Paula. Karla é do grupo dos Figurantes na aula e Brenda é das Excluídas; quando perguntadas sobre se recebem algum incentivo da família relataram:

K: Recebo, meus pais sempre falam "você tem que fazer atividade fisica!" Meu pai e minha mãe estão sempre me colocando para fazer caminhada.

B: Incentivo eu não sei, mas minha mãe sempre fala que eu vou virar uma baleia gorda se eu não fizer nada.

Naomi Wolf (1992) afirma ser a beleza uma forma de sistema monetário que atribui valor as mulheres "de acordo com o padrão físico imposto culturalmente" (WOLF, 1992, p. 15). A autora também defende a ideia de que é obrigação das mulheres encarnar a beleza e atingir os padrões culturais impostos em relação a sua imagem. Dessa forma, o apoio social na forma de incentivos em discursos voltados para saúde e estética apareceu mais como cobrança das famílias das meninas para uma postura mais ativa do que apoios para o aprendizado que 
proporcionasse vivências significativas e compreensão dos conteúdos da cultura corporal. Estava associada a esses apoios a ideia de que é obrigação das mulheres encarnarem uma imagem de beleza, um padrão estético. Pensando também nas diferenças de aprendizados proporcionados pelas atividades em que as meninas e meninos mais recebem apoio social, temos que as caminhadas e ginásticas são atividades individuais, que apesar de poder haver uma socialização entre as pessoas praticantes, nessas práticas corporais não há necessidade de se relacionar com outras/os companheiras/os da mesma maneira que nos esportes coletivos. Nos esportes coletivos, entre várias características, há necessidade de associar ações individuais às de uma equipe, são práticas competitivas em que há o enfrentamento de adversários. Tais características possibilitam experiências corporais e de socialização bastante distintas das que as práticas individuais como a caminhada e ginástica de condicionamento. Além disso, essas duas atividades (caminhada e ginástica de condicionamento) são práticas corporais que promovem um repertório de experiências com o corpo que pouco se assemelham aos conteúdos das aulas de educação física que nas escolas observadas eram sempre de jogos coletivos e de princípios esportivos.

\section{Considerações finais}

As maneiras de participar das aulas são muito mais complexas do que uma lógica binária pensada em Participar X Não participar. Conforme Jacques Derrida(1991) aponta, ao se pensar através dos binarismos, estabelecemos um elemento como sendo o centro, o positivo, e o outro como sendo o oposto, o negativo. Sendo assim, nesse entendimento de Participar X Não Participar, entende-se que estar na atividade é participar, o positivo; estar fora seria o oposto. No entanto, existem várias maneiras de ser e estar nas aulas, formas que neste trabalho foram identificadas como participações Protagonistas, Figurantes, Flutuantes e Excluídos.

Notou-se que a maioria das pessoas que ocupam o lugar de Protagonista nas aulas teve também experiências de aprendizado com as práticas corporais em espaços formais de ensino fora da escola. As práticas em "escolinhas" de esporte, academias e clubes contribuíram de maneira significativa para que essas pessoas tivessem destaque nas aulas de educação física, pois as aulas observadas acabavam por privilegiar momentos de prática de esportes e de demonstração de habilidades. Sendo assim, as aulas acabavam privilegiando a participação de quem já dominava os conteúdos, domínio que havia sido estabelecido, sobretudo, em práticas fora da escola.

Por isso, é possível dizer que, nas aulas observadas, o que alunos e alunas traziam de fora da escola em relação às experiências e conhecimentos sobre o corpo e o movimento tinha grande influência sobre qual lugar esses/as alunos/as ocupavam nessas aulas. Isso porque não são a escola e a educação física as únicas responsáveis pelos entendimentos e usos do corpo 
de alunos/as. O meio cultural no qual estavam inseridos/as possibilitou experiências e entendimentos distinto para cada um/a sobre os saberes que circulam nas aulas de educação física. A maioria das pessoas protagonistas tiveram experiências com esportes fora da escola, conteúdo próximo ou igual ao das aulas. Como as aulas privilegiavam momentos de demonstração de habilidades, essas pessoas que já dominavam os conteúdos da aula acabavam se destacando e ocupando o lugar de protagonistas, enquanto quem "não sabia" os conteúdos tinha poucas possibilidades de vir a saber. Isso influenciou em uma menor participação dessas pessoas, o que foi tanto promovido por quem "sabia" e que não possibilitava uma interação no jogo dessas pessoas que tinham mais dificuldade, tanto por elas próprias, que sentiam vergonha de expor seus erros e por isso interagiam pouco na atividade.

"Saber" ou "Não Saber" os conteúdos da aula também está relacionado com os entendimentos de gênero e prática corporal. As experiências fora da escola de meninos foram, sobretudo, com modalidades esportivas coletivas, enquanto somente as poucas meninas protagonistas tiveram as mesmas vivências. Os discursos sobre os cuidados com corpo voltados para a saúde e estética foram os que prevaleceram para as meninas, o que promovia experiências com práticas individuais que colaborassem com tais aspectos. Sendo então bastante distintas as experiências da maioria das meninas quando comparadas com as dos meninos. As experiências das meninas em pouco se assemelhavam com os conteúdos das aulas, além disso, tais diferenciações mostraram o quanto ainda estão presentes os discursos sobre as práticas corporais como sendo generificadas, ou seja, adequadas para cada gênero.

Este trabalho não definiu toda a complexidade que afeta o contexto das aulas de educação física e os sujeitos envolvidos, mas contribui para novas possibilidades de compreender as diferentes maneiras de participar das aulas de educação física e como essas maneiras se entrelaçam com os entendimentos de gênero. Como sabemos, em ciências humanas, as compreensões e entendimentos sobre um assunto nunca estão acabadas, definidas e tornadas sinônimos de verdades, mas nem por isso perdem sua função o seu valor. Por isso, as discussões apresentadas até aqui, merecem ser consideradas, problematizadas, ampliadas e, quem sabe, reapresentadas a partir de outros elementos produzidos em outras experiências.

\section{Referências}

ALDEMAN, M. Mulheres atletas: re-significações da corporalidade feminina. Estudos Feministas, Florianópolis, v.(11) n.(2), p.445-465, julho-dezembro/2003. 
ANDRADE, E. B; DEVIDE, F. Auto-exclusão nas aulas de educação física escolar: representações de alunas do Ensino Médio sob enfoque de gênero. FIEP Bulletin, Foz do Iguaçu, v. (76) , p. 318-321, 2006.

BRACHT, V. A constituição das teorias pedagógicas da educação física. Cadernos Cedes. Ano XIX, n. 48, p. 69-88, ago., 1999.

BUTLER, J. Problemas de gênero: feminismo e subversão da identidade. Rio de Janeiro: Civilização brasileira, 2003.

DELGADO, D. M.; PARANHOS, T. L. Fatores que levam a não participação das alunas nas aulas de educação física escolar no ensino médio. Trabalho de Conclusão de CursoUniversidade Estácio de Sá. Rio de Janeiro, 2009.

DERRIDA, J. Margens da filosofia. Trad. Joaquim Torres Costa e Antonio M. Magalhaes. Porto: Rés-Editora, 1991.

GEERTZ, C. A Interpretação das Culturas. Rio de Janeiro: Guanabara Koogan S.A., 1989.

GOELLNER, S.V. Imagens da mulher no esporte. In: PRIORE, M. D.; MELO, V. A. de (orgs). História do Esporte no Brasil: do Império aos dias atuais. São Paulo: Editora Unesp, 2009.

HALL, S. A centralidade da cultura: notas sobre as revoluções culturais do nosso tempo. Educação e Realidade. Porto Alegre, v (22), n.(2), p. 17-46, julho/dezembro 1997.

JACO, J. F. Educação Física e Adolescência: "Professor, não vou participar da aulas!" Trabalho de Conclusão de Curso- Faculdade de Educação Física Universidade Estadual de Campinas, Campinas, 2008.

OLIVEIRA, R. C. Na "Periferia" da quadra: Educação Física, cultura e sociabilidade na escola. Tese de Doutorado. Faculdade de Educação Física, Universidade Estadual de Campinas, 2010.

PEREIRA, R. S. \& MOREIRA, E. C. A participação de alunos do ensino médio em aulas de Educação Física: Algumas considerações. Revista da Educação Física/UEM. Maringá, v. (16), n.(2), p. 121-127, 2005.

RIGONI, A. C .C. Educação do corpo e religião: questões à educação física escolar . In: DAOLIO, J. (coord.) Educação Física Escolar: Olhares a partir da cultura. Campinas: Autores Associados, 2010. 
SCOTT, J. Gênero: uma categoria útil de análise histórica. Educação \& Realidade, Porto Alegre, v.(20), n.(2), p.71-99. Jul./ Dez., 1995.

SOARES, C. L. Educação Física escolar: conhecimento e especificidade. Revista Paulista de Educação Física, São Paulo, supl.2, p.6-12, 1996.

VALLE, M. T. E. do. Não saber/ Ainda não saber/ Já saber: Pistas para a superação do fracasso escolar. Dissertação de Mestrado. Faculdade de Educação, Universidade Federal Fluminense, Niterói, 1992.

WOLF, N. O Mito da Beleza: Como as imagens de beleza são usadas contra as mulheres. Tradução: Wáldea Barcellos. Rio de Janeiro: ROCCO, 1992.

Recebido em: 01/07/2014

Revisado em: 13/04/2015

Aprovado para publicação em: 23/03/2016

Publicado em: 30/04/2016 